\title{
LA CORDILLERA DE LOS ANDES EN EL NORTE DE PATAGONIA O LAFRONTERA ARGENTINO-CHILENA COMO ESPACIO SOCIAL. UN ESTUDIO DE CASO
}

\author{
Por \\ Lic. Susana O. Bandierie*
}

\begin{abstract}
RESUMEN
En este trabajo se muestra la permanencia de las relaciones socioeconómicas y culturales en la región fronteriza del Neuquén, que se ubica entre Chile y Argentina; en donde la imposición de límites jurídico-administrativos noafectó su funcionamiento ni la expresión territorial de la ganadería extensiva como actividad dominante. La descomposición de esta región se presentó a partir de 1930 , con la fijación de una frontera comercial que provocó una crisis generalizada en la actividad ganadera. Esto trajo como consecuencia el incremento de su marginalidad socioeconómica y un proceso de despoblamiento de la región.
\end{abstract}

\begin{abstract}
This work shows the durability of socio-economic and cultural ralations in Neuquen border region, located between Chile and Argentina, where the imposing of legal-administrative limits did not affect its functioning nor the territorial expresion of intensive cattling as a dominant activity. The decomposing of this region began in 1930 with the establishment of a commercial boundary, which caufed a general crisis in the cattling activities. This brought, as a consequence, the increase in its socio-economical marginality and a depopulating process of this region.
\end{abstract}

\section{INTRODUCCIÓN}

El objetivo de este trabajo es mostrar la perdurabilidad histórica de las relaciones económicas, sociales y culturales entre el área noroccidental de la Patagonia argentina - particularmente la Provincia de Neuquén-y la nación chilena. Hasta bien entrado nuestro siglo, la cordillera de los Andes fue más que un límite natural o una frontera política, el eje vertebrador de un espacio socialmente integrado. Características físicas e histórico-sociales posibilitaron que, tradicionalmente y desde épocas muy remotas, el territorio neuquino funcionase como parte de la región económica del sistema urbano chileno c hinterland de los principales puertos de ese país sobre el océano Pacífico.

- Prof. y Lic. en Historia. Docente en la Universidad Nacional del Cornahue (Neuquén-Argentina) y becaria del Consejo Nacional de Investigaciones Científicas y Técnicas (CONICET), Buenos Aires, Argentina. 
El avance de las fuerzas militares sobre las comunidades indígenas de la Patagonia — campañas punitivas entre los años 1879 y 1885, al incorporar definitivamente la región al territorio que se define como nación argentina-, trajo como correlato inmediato la imposición de una organización territorial acorde con el nuevo esquema de dominación. Es así como se impusieron límites jurídico-administrativos, se dispuso la fundación de pueblos, se estableció una capital como centro político de autoridad máxima dentro del espacio y se pretendio afirmar la frontera internacional en la cordillera de los Andes. Sin embargo, el límite fronterizo (argentinochileno) impuesto a la región no afectó su funcionamiento ni la expresión espacial de la ganadería extensiva como actividad dominante. Características estructurales de la misma provocarían la supervivencia de las viejas formas de organización social y de algunas características de la sociedad indigena, derivadas de la perdurabilidad en las modalidades de uso de los recursos y del espacio social que tomaba como eje la cordillera, que no se acabaron con la mera ocupación blanca del espacio y su consiguiente incorporación a las formas capitalistas de producción.

Este tradicional funcionamiento de la región fronteriza, como espacio socialmente integrado, comenzó a sufrir su primera descomposición a partir de 1930, cuando ambos estados - Chile y Argentina - en diferentes momentos y por distintas razones inherentes a sus propias circunstancias históricas y derivadas de la coyuntura internacional, consolidaron sus situaciones territoriales a través de la fijación de una frontera comercial. En la década de 1940, la situación tuvo aún un corte más definitivo, cuando la fase de industrialización de las economías nacionales impuso en el área mayores barreras aduaneras. La descomposición de las modalidades de comercialización provocó una crisis generalizada de la actividad ganadera dominante, afectando seriamente a los distintos actores sociales vinculados a la misma, particularmente a los pequefios productores ocupantes de tierras fiscales que vieron cortadas sus posibilidades de acceder a la obtención de un excedente mediante el intercambio directo en las áreas de frontera, pasando a depender de sucesivas etapas de intermediación comercial para poder acceder al mercado nacional argentino. Todo cllo ha incidido en el incremento de su marginalidad socioeconómica y en el proceso de despoblamiento de gran parte del interior rural neuquino en beneficio de su ciudad capital. ${ }^{1}$

1 "Ubicada en el extremo noroeste de la Patagonia con una superficic de $94.078 \mathrm{~km}^{2}$, la provincia de Neuquén es la más pequeña entre las de la región, constituyendo el 3.4\% del territorio continental, y con una población de 243.850 habitantes que representan aproximadamente el $0.9 \%$ del total de la población del país (...) El territorio neuquino tiene una forma triangular con amplia base recostada sobre la cordillera de los Andes y el vértice opuesto sobre la confluencia de los ríos Neuquén y Limay, mediando espacios desérticos 


\section{LAS COMUNIDADES INDÍGENAS Y LA ORGANIZACIÓN SOCIAL DEL ESPAC $t, O$}

Del permanente y fluido traspasar de la cordillera se fueron gestando en Neuquén características de especial singularidad cultural visibles ya en los grupos indigenas que poblaron el territorio. Sin entrar a especificar la difícil determinación de las etnias que ejercieron la ocupación real del espacio neuquino a la llegada de los españoles, nos interesa recalcar en particular el proceso de araucanización que lenta y gradualmente provocaría una notable simbiosis cultural entre las tribus de ambos contrafuertes andinos. Antes de este proceso, pehuenches, puelches, poyas, fueron descritos, por las crónicas de los conquistadores espafioles que desde Chile llegaron a Neuquén, con caracteres físicos y culturales distintos de los araucanos de la falda occidental de los Andes.

hacia el mar, los puertos y la región pampeana. Esto contribuye a otorgarle características de mediterraneidad y aislamiento que han influido decisivamente en la importancia que ha 'marcado históricamente su desarrollo y su rol en el norte de la Patagonia.

El espacio provincial está definido por límites políticos: al oeste la cordillera de los Andes sirve de límite intemacional con la república de Chile; al norte los ríos Colorado y Barrancas la separan de Mendoza hasta la intersección con el meridiano $68^{\circ}, 15^{\prime}$ de longitud oeste; al este continúa por el meridiano en cuestion hasta el río Neuquén: y luego por el Limay hasta el lago Nahuel Huapi que en su parte más profunda la separa del río Negro.

Su posición occidental la aleja de los principales puentos atlánticos, pero en cambio resulta ventajosa la comunicación con Chile. En estas latitudes la cordillera es más baja y son cada ver más frecuentes los valles transversales a escasa altura. Esta ubicación favorable fue aprovechada desde tiempos históricos por los indígenas de la zona que pasaban al pás vecino para colocar ganado y comerciar libremente. La escasa altura de algunos pasos y las condiciones climáticas menos rigurosas que en las provincias más australes, permiten el uso de los mismos durante todo el año, en una buena parte de este sector de la cordillera de los Andes". (Atlas de la provincia del Neuquén, s/f:10).

“... La fisonomía de la región es variada y los recursos abundantes contrastan con una densidad de población relativamente baja. Lagos de origen glaciario y montantas cubiertas de confferas que reciben las precipitaciones más copiosas del pafs dominan los paisajes occidentales. En cambio, el sector central se caracteriza por la presencia de las áridas mesetas patagónicas. Centenares de arroyos y ríos recorren la zona cordillerana y forman luego el amplio sistema de los ríos Limay, Neuquén y Negro que junto con el Colorado y el Atuel son los principales recursos de agua de la región. Pero la mayor parte del territorio soporta en mayor o en menor medida una aridez que ha contribuido a condicionar su fisonomía. Así, las actividades guardan una estrecha relación con las características topográficas y climáticas. El riego resulta por lo tanto el sostén fundamental de la agricultura intensiva de los valles. El resto del espacio regional está dedicado principalmente a la ganadería ovina y caprina, oumamente extensiva que ocupa poca mano de obra y que como consecuencia del bajo nivel tecnológico deja una débil impronta en el medio natural (...) En la porción del territorio chileno que se encuentra a la misma latitud de Neuquén se localiza una área densamente poblada, con ciudades de la magnitud de Concepción, Temuco, Valdivia, Osomo y Puerto Montt. Esta área estuvo tradicionalmente vinculada a Neuquén (...) la circulación económica entre las dos regiones es, no obstante, poco desarrollada (escasa o casi nula)" - - re refiere a la actualidad- (Atlas de la provincia del Neuquén, s/f:12) (Subrayado del autor). 
Estas etnias locales sufrieron un verdadero impacto con la penetración física y cultural de los araucanos (mapuches de Chile). La primera, posiblemente provocada por la presión de los grupos incaicos hasta el sur de Chile o como efecto del sistema de explotación de la mano de obra indígena impuesta por los españoles y, posteriormente, por el propio corrimiento de la frontera interna chilena, que logró la dominación de las antiguas parcialidades de la zona e incluso conformar nuevas como producto de la mestización. La segunda, que llamamos penetración cultural, se agregó a la primera bajo la forma de un viejo y permanente contacto entre las distintas etnias, favorecida por la accesibilidad de la cordillera de los Andes en Neuquén. Durante el verano, luego del deshielo, comenzaba el activo intercambio, bajo la forma de trueque, de caballos, plumas de avestruz, mantos de pieles a cambio del maíz y otros productos que los mapuches cultivaban en la vertiente occidental de los Andes.

Esta doble penetración, física y cultural, culminó en un verdadero proceso de simbiosis llamado "de araucanización" que se acentuó especialmente a partir del sigloXVII. ${ }^{2}$ El notable impacto de la culturaaraucana se hizo evidente en los primitivos pueblos cazadores y recolectores de Neuquén. La lengua es quizás su expresión más completa. A su vez, al trasplantarse al Neuquén, los grupos mapuches de Chile - agricultores y ceramistas - modificaron su organización económica al dedicarse primordialmente a la caza y comercio de ganado, primero cimarrón y luego - a medida que la propiedad privada se afianzó en la pampa argentina- a la actividad malonera. ${ }^{3}$ Vemos claramente cómo la topografía del territorio determinó la organización económica de la población indígena; el traslado continuo de haciendas a Chile, siempre a través de la cordillera de los Andes, se transformó en el elemento de base de la organización socioeconómica de estos pueblos.

Los hacendados chilenos requerían ganado para el consumo interno y para exportar a otros pueblos del Pacífico, y los indígenas del Neuquén

2 Para 1879, año en que se realizaría la llamada campaña al desierto o conquista definitiva por los blancos de los territorios patagónicos ocupados por el indio, el proceso de araucanización era total en toda el área.

3 Con la difusión del ganado vacuno y caballar introducido por los españoles, que en la libertad de las llanuras argentinas se convirtieron en bienes de propiedad común, se alteró profundamente la actividad económica y modo de vida de estos pueblos. La disminución del número de animales "cimarrones", por efecto de la matanza indiscriminada llevada a cabo en las vaquerías, y la posterior formación de la estancia - avanzada la primera mitad del siglo XIX - como unidad productiva que refleja el avance de la propiedad privada de los medios de producción -incorporación del alambrado-, disminuyeron y dificultaron las posibilidades de conseguir aquel bien que se había convertido en la base fundamental de su forma de vida: el ganado vacuno, bien de consumo y de cambio. Por ello la cada vez mayor recurrencia al malón como forma de avanzar sobre la llanura pampeana y conseguir el otrora bien común y ahora bien privado. 
actuaban como excelentes intermediarios. Las haciendas, producto de la actividad malonera, eran arriadas desde la pampa húmeda por rastrilladas que atravesaban el país y que entraban en Chile por más de un centenar de boquetes en que la cordillera neuquina facilitaba el traspaso.

Dice al respecto el Gral. Manuel J. Olascoaga, miembro de las fuerzas expedicionarias de Roca y futuro primer gobernador del territorio del Neuquén:

Recordando "...las connivencias en que siempre han estado y están nuestros indios de la cordillera y de la pampa con los comerciantes chilenos y aún con el gobierno de Chile..." señala "...vienen a Buenos Aires, Santa Fé, Córdoba y San Luis, regresando con grandes trozos de haciendas por los últimos pasos al sur del Salado, río Grande y Neuquén, para ir a entrar a Chile por Villa Rica, donde la cordillera hace un abra de cerca de una legua de ancho, que es por donde pasa el camino más frecuentado por los indios de la pampa y que existe entre el sur de Buenos Aires y Chile. Tengo un amigo en Valdivia que me asegura que por el expresado camino han cruzado en algunos inviernos hasta 2,000 indios". (Olascoaga, 1974:37-39).

Comenta respecto a la magnitud de las rastrilladas indias:

“...experimentamos no pequeña sorpresa al ver por todas partes verdaderas carreteras que, por las innumerables sendas que las forman y los despojos de animales demuestran un tráfico continuo desde la fecha remota (...) el piso retraqueado, duro; hondas sendas a dos pies de distancia unas de otras, ocupando entrelazadas y paralelamente una extensión de dos millas; los huesos en descomposición de distintas fechas, todo indicando el tráfico constante desde siglos atrás hasta el presente, de millones de hombres y animales. No son estos grandes carriles las huellas de reducidas tribus nómadas que han cruzado cuatro o seis veces por año con ocasion de sus merodeos. Son toda una vialidad entre grandes centros comerciales; son las verdaderas arterias de comunicación por donde va la vida, la riqueza y el progreso de unos pueblos a otros." (Olascoaga, 1974:165-66).

La decisión de incorporar las tierras patagónicas al control del poder nacional mediante una definitiva expedición punitiva - la llamada Campaña del desierto del Gral. Julio A. Roca en $1879^{4}$ - suele atribuirse, en

\footnotetext{
4 La definitiva expedición militar sobre el indio, llamada "Campaña al desierto", refleja en su misma denominación la concepción ideológica de los sectores dominantes que la llevaron a cabo. Efectivamente, el término "desiento" se utiliza aquí más con un sentido social que ecológico y se le transforma en sinónimo de "barbarie" o lo que es lo mismo "vacío de civilización".
} 
términos generales, a la doble necesidad de terminar con la señalada actividad de los indígenas y a la de incorporar nuevas tierras a la producción ganadera destinada al mercado externo - recordemos la afirmación de Argentina en el siglo XIX como país capitalista dependiente productor de materias primas y alimentos-, lo que provocaría el desplazamiento del ganado ovino desde la llanura pampeana a las nuevas tierras ganadas al indio. Sin embargo, creemos que en el particular caso del territorio neuquino, que no sufrió el impacto del corrimiento ovino que sí se visualiza en el resto de Patagonia, el objetivo primordial puede aún ser más específicamente acotado. Se trataba de cortar definitivamente con la amenaza del modus vivendi de ese espacio integrado socioeconómicamente y que afectaba directamente los intereses de la clase más poderosa de Argentina, aquélla que se arrogaba representar los intereses de la nación, la burguesía terrateniente dueña de los latifundios más productivos del pafs, cuyos ganados iban a parar a Chile mediante la eficaz intermediación de los malones indios. Había que cortar la "...subsistencia de la llaga de la cordillera, que es la llaga de la república." (Olascoaga, 1974: 40)

También el Gral. Roca, jefe de la expedición militar, es claro al respecto:

"No solamente ofrecería esta operación grandes beneficios para el país, por los riquísimos campos regados por los numerosos ríos y arroyos que se desprenden de la cordillera (...) sino por las ventajas que reportaría para la seguridad de nuestras fronteras actuales el hecho de interceptar y cortar para siempre el comercio ilícito que desde tiempo inmemorial hacen con las haciendas robadas por los indios las provincias del sur de Chile: Talca, Maule, Linares, Nuble, Concepción, Arauco y Valdivia.

En épocas normales, en que no se tienen en cuenta las grandes invasiones, como las realizadas últimamente que aumentan considerablemente la exportación de ganados para Chile, se calcula la cantidad de ganado robado en nuestras provincias en cuarenta mil cabezas al año, cuya mayor parte la venden los pehuenches que viven en perfecta paz y armonía con la república chilena, recibiendo en cambio, en especies, un valor en dos o tres pesos fuertes por cabeza. Algunas personas que han vivido en las fronteras chilenas me han asegurado que algunos de los prohombres de aquel país que tienen o han tenido grandes establecimientos de campo en aquellas provincias, no han sido extraños a este comercio y deben a él sus pingües fortunas o el considerable acrecentamiento de ellas.

Abrigo la convicción de que suprimido este mercado, que hace subir o bajar las haciendas en Chile, en proporción a la importancia de los malones dados a Buenos Aires o a otras provincias argentinas se quitaría a los indios el más poderoso de los incentivos que 
los impulsaba a vivir constantemente en acecho de nuestra riqueza (...) Hay caciques que hacen de capataces de hacendados chilenos y reciben en guarda miles de ganados que devuelven religiosamente después de invernados (...) Otras veces arriendan sus tierras y los ganaderos chilenos suelen vivir largas temporadas entre ellos, sin que sufran sus intereses. Se calcula que sólo en esa parte - se refiere al norte de Neuquén-se invernan en los potreros naturales que forma la Cordillera de 20 a 30 mil cabezas anualmente." (Carta del Gral. Roca al redactor de "La República", en: Olascoaga, 1974:76-80) (subrayados del autor).

En efecto, los primeros contactos de las expediciones punitivas con el territorio del Neuquén - minuciosamente registrados en las partes militares- no hicieron más que confirmar esta marcada integración de los pueblos de ambos lados de la cordillera. Aún más, prueban también que las prácticas agrícolas de los mapuches chilenos prendieron en Neuquén por efectos del proceso de araucanización oportunamente aludido y determinaron asentamientos indígenas de relativa estabilidad, tal cual lo demuestran las siguientes afirmaciones:

"Más de 200 cuadras sembradas rodean los toldos abandonados - se refiere a las tolderías abandonadas y quemadas por los indios en su retirada hacia la cordillera- (...) varios ranchos de indios recientemente abandonados y los rastrojos con señales de riego por medio de acequias manifiestan que este lugar ha sido ocupado con alguna preferencia por las tribus que ahora se encuentran del otro lado del Neuquén - se refiere al río de ese nombre- (...) tienen mucho ganado y son sembradores (...) Los habitantes de Malbarco y de todos estos puntos exportan sus ganados y hasta los granos de sus sementeras a Chile, proveyendo a las necesidades de los indios con artículos introducidos de Chillán y otras plazas próximas a la cordillera..." (Distintas partes militares en: Olascoaga, 1974:147-361) (subrayado del autor).

Avanzado el siglo XIX, al tomar forma concreta la inserción de Argentina en el mercado internacional como país productor de bienes primarios, basada su economía en la ganadería extensiva y conformada la estancia como unidad productiva capitalista, la hacienda cimarrona -base de la organización socioeconómica comunitaria de la nación indígena y producto fundamental del secular intercambio con Chilecomenzó a escasear y aun a desaparecer. Ello incentivó la práctica del malón en los grupos indígenas que afectó en forma directa los intereses de los grupos ganaderos bonaerenses en tanto sectores dominantes en el modelo de desarrollo vigente. 
Extender y consolidar definitivamente la móvil frontera interior del país fue entonces preocupación esencial de los distintos gobiernos y objeto de políticas diversas durante toda la primera parte del siglo XIX. Una serie de conflictos internos, a los que se sumó la guerra con el Paraguay, habían demorado y hasta paralizado el avance de la frontera con el indio, pero la permanente amenaza sobre el sector productivo más fuerte del país, vinculado al mercado internacional, llevó a concreciones más definitivas subsidiadas por ese mismo sector. Desde la llamada "Campaña al desierto" en adelante, las sucesivas etapas en que se planeó el definitivo sometimiento del indio tuvieron como escenario la fase final al territorio del Neuquén $\longrightarrow$ territorio del "triángulo" como se le denominaba en la época-, cuya especial topografía le confería condiciones de aislamiento favorable a los últimos reductos indígenas en sus intentos defensivos -inútiles por otra parte ante la superioridad tecnológica del ejército nacional-.

A la llegada de las fuerzas militares ningún asentamiento blanco argentino habíaen Neuquén. Hasta donde sabemos, sólopobladores chilenos compartían el espacio con los indígenas en una convivencia socioeconómica generalmente sólida, como lo demuestra el asentamiento de Malbarco mencionado y descrito en las partes militares. Se considera oportuno destacar el nivel de complejidad de este asentamiento, ubicado en el extremo noroeste del territorio, que fue descrito en la época con una población aproximada de 600 habitantes entre indígenas, puesteros y hacendados chilenos que arrendaban terrenos a los caciques comarcanos (Olascoaga, 1974:78, 368-369). Esta población parece haber existido desde tiempos muy remotos -1,752 según el misionero Havestadt-, incrementándose luego por las especiales condiciones del lugar para la engorda del ganado que se arreaba desde las llanuras bonaerenses y se vendía del otro lado de la cordillera. Dos estancieros, Méndez Urréjola y Price, estaban sólidamente instalados en la zona al momento de producirse la avanzada militar "contra el desierto", con importantes establecimientos ganaderos en tierras que arrendaban a los picunches. Indígenas y chilenos mantenían una particular convivencia en Malbarco; donde los funcionarios del país vecino extendían de hecho su autoridad a través de la presencia de subdelegadosciviles, aunque reconociendo la base de poder de los caciques locales al propiciar el arriendo de sus tierras o la firma de tratados tendientes a obtener un trato favorable "con las personas y haciendas de los chilenos comerciantes o residentes del otro lado de la cordillera".

5 Tratado del $1^{2}$ de enero de 1872 entre el jefe de operaciones de frontera e intendente de la provincia de Arauco, Gral. Basilio Urrutia, en representación del gobiemo chileno y embajadores y representantes de las tribus del Neuquén. 
Por otra parte, la presencia de asentamientos indígenas sedentarios, o cuasi sedentarios, en otras partes del territorio — según se desprende de la simple lectura de las mismas fuentes militares-con existencia de rebaños y corrales y manifestaciones agrícolas que incluían el riego por medio de acequias, así como la constatada práctica de la trashumancia - característica especial de la ganadería neuquina consistente en el traslado temporario de las haciendas de campos bajos de invernada a campos altos de veranada - obligan, por un lado, a descartar el generalizado nomadismo y prácticas económicas exclusivamente recolectoras y depredatorias atribuidos a estos pueblos y, por el otro, a tener presente estos aspectos para reconocer, en el estudio de la organización social posterior, la persistencia de cierto tipo de relaciones así como la perdurabilidad de las formas de uso de los recursos y del espacio social, que toma como eje la cordillera de los Andes, y las modalidades de la sociedad indígena que no se acaban con la mera ocupación militar del espacio.

Efectivamente, las características mencionadas aparecían como comunes en la segunda mitad del siglo XIX a toda la zona oeste del Neuquén, justamente aquélla que por sus características fisiográficas -área cordillerana y antecordillerana - admitía tales actividades. La zona este del territorio, con características más semejantes a la meseta patagónica, sólo se presentaba como lugar de tránsito del activo comercio ganadero con Chile. No debe olvidarse que la ubicación geográfica del territorio y su topografía también determinaron uno de los elementos claves de la organización económica de estos pueblos: el traslado de haciendas a través de la cordillera de los Andes. Los indígenas del Neuquén fueron una pieza fundamental en el amplio circuito mercantil que unía a la producción ganadera de la llanura pampeana con los mercados consumidores del Pacífico.

En resumen, las modalidades de la formación social indígena analizadas parecen haber caracterizado la primera etapa en la ocupación del espacio regional con una actividad agrícola-ganadera emplazada esencialmente en los faldeos cordilleranos. La primera, agrícola, más vinculada al consumo interno de la comunidad indígena y la segunda, ganadera, como elemento base de un activo intercambio comercial con las ciudades y puertos chilenos. El área cordillerana y antecordillerana del territorio neuquino aparecía ya funcionando en esta etapa como región de esos centros (Chillán, Angol, Antuco) e hinterland de los principales puertos sobre el Pacífico a esa latitud (Valdivia y Concepción).

A partir de la ocupación del territorio por las fuerzas militares argentinas, hecho sin duda favorecido por la simultánea participación de Chile en la guerra del Pacífico, se trataría de imponer una organización territorial acorde con el nuevo esquema de dominación. Es así como, a partir de un 
concepto de seguridad estratégico militar, se dispuso la creación de pueblos, se estableció una capital como centro político de autoridad máxima dentro del espacio - Chos Malal- y se pretendió afirmar la frontera política en la cordillera de los Andes. Sin embargo, características estructurales de la actividad ganadera dominante provocaron la supervivencia de viejas formas relictuales de organización social, heredadas de la ctapa previa a la conquista militar.

Por otra parte, la incorporación del espacio indígena al territorio que se define como nación argentina trajo como correlato inmediato la apropiación privada de la tierra como recurso productivo. Al desposecr a estas comunidades de sus condiciones naturales de producción y transferirlas a nuevos dueños se asentarían las bases de una formación social diferente, integrada al sistema nacional e internacional vigente. A partir de cse momento, las distintas modalidades de acumulación capitalista de excedentes diferenciaron los asentamientos. Aquéllos que conformaron el área de interés de este trabajo scrán analizados en función de la evolución histórica de la actividad predominante.

\section{EL AUGE DEL CICLO GANADERO REGIONAL 1879-1930}

Hacia los inicios de esta etapa, la expansión económica del país, hasta ese momento predominantemente pecuaria, exigía la incorporación de nuevas tierras que aliviaran la presión pastoril sobre las llanuras bonaerenses, a la vez que permitieran el incremento de los volúmenes de producción para una correcta respuesta a la demanda europea de lanas y carnes. $\mathrm{La}$ expansión de la frontera interna respondió también a este objetivo implícito de volcar a tierras marginales la ganadería excedentaria en las viejas zonas ocupadas. Sin embargo, el corrimiento ovino, que luego de la campaña militar de 1879 incorporó a la Patagonia al sistema económico nacional e internacional afectó sólo a los territorios con litoral atlántico, no extendiéndose a Neuquén donde perduraron formas de organización socioeconómicas heredadas de la etapa anterior. Características físicas e histórico-sociales posibilitaron que tradicionalmente y, según vimos, desde épocas muy remotas, el territorio funcionase como parte de la región económica del sistema urbano chileno.

Cabe recordar al respecto las características de la estructura económica dominante en Chile. Interesa destacar particularmente la importante gravitación de la agricultura durante la segunda mitad del siglo pasado, en una expansión favorecida por los descubrimientos de oro en California y Australia y por una continua y creciente demanda de los países europeos (en especial Inglaterra). En las primeras décadas de la segunda mitad del 
siglo XIX, la producción agrícola chilena lleg 6 a cuadruplicarse, que junto con el cobre, fue uno de los rubros de exportación más favorecidos. Valparaíso se convirtió en la plaza portuaria más importante del Pacífico sur.

La expansión agrícola mencionada estuvo directamente relacionada a las características de monoproducción cerealera que reflejaban las provincias del sur chileno hacia los mismos años. Por tal motivo, es dable inferir la importancia que para el mercado trasandino tenía la obtención de carne -en especial vacuna- sin afectar sus propios recursos, ya sea como complemento alimentario de su mercado interno o para cubrir - vía sus propios puertos- las demandas de sebo, cuero y tasajo de otros paises sudamericanos con costas sobre el Pacífico, como Perú y Ecuador. Según Vicuña Mackena, citado por Assadourian (1982:57), el siglo XVII había sido en Chile el "siglo del sebo" y la ciudad de Concepción - téngase en cuenta su proximidad con el territorio neuquino- concentraba la producción masiva de ese producto con destino a los mercados del Pacífico. Luego, la especialización cerealera mencionada provocó la expansión de la frontera agrícola del valle central chileno hacia el sur, aumentando consecuentemente los requerimientos de carne y derivados para consumo y exportación. Grandes cantidades de ganado en pie (de buen peso y escasa calidad) cran demandadas como materia prima para actividades de transformación (curtiembres, graserías, fábricas de jabón, saladeros), cuyo peso y posibilidades de colocación eran importantes en la época.

A estas condicionantes histórico-sociales cabe agregar características físicas de singular importancia que hacían del territorio neuquino, por su ubicación al este de la cordillera de los Andes, un lugar dotado de excelentes condiciones para satisfacer tal demanda. Nos referimos particularmente a sus mejores aptitudes ecologicas: bosques menos densos, pasturas naturales adecuadas para alimentación del ganado, valles transversales que facilitan el tránsito de un lado a otro de la cordillera. Chile, en cambio, posee, en igual latitud, áreas muy boscosas poco aptas para ganadería, con la sola excepción de los valles que ya estaban ocupados por la agricultura.

Podemos afirmar entonces que, cuando las principales regiones productoras argentinas apuraban el proceso de refinamiento de razas carniceras con destino al frigorífico y, vía la cxportación, al mercado europeo, Neuquén producía ganado para la especial demanda de los centros chilenos. Esta situación se vio asimismo favorecida al comienzo de la etapa que nos ocupa, por el hecho de que Mendoza, tradicional proveedora de ganado a Chile, incrementara en la misma época su producción vitivinícola, transformando sus potreros alfalfados en campos de vides.

En los territorios patagónicos con litoral atlántico el incremento del ganado ovino fue sustancialmente importante hacia principios de siglo, en 
tanto que en Neuquén las cifras eran poco representativas y reflejaban, en términos generales, una marcada estabilidad (Baldieri, 1983). Entendemos que esto se debió en especial a las limitadas posibilidades de colocación de la producción ovina en el mercado de la zona sur de Chile, acorde con la estructura económica dominante que describimos. En principio, podemos entonces inferir que la generalizada especialización ovina con destino al mercado europeo, que se atribuye a Patagonia, no incluyó al territorio que nos ocupa.

El bovino, en cambio, aunque muy poco significativo a nivel de existencias totales del país, aparecía desde los primeros relevamientos censales con un peso importante a nivel regional, en tanto registraba la mayor cantidad de cabezas con respecto al resto de Patagonia. Ello también se explica en función del mercado chileno demandante de ganado en pie para consumo y exportación a otros puertos del Pacífico y como materia prima indispensable para actividades de transformación. Nos referimos particularmente, según se vio, a la industria del saladero, curtiembres y a la fabricación de sebo y otros derivados como el jabón. Por ello, fue el ganado de tipo "criollo" el predominante absoluto en los primeros registros censales.

Por otra parte, en caprinos Neuquén ocupó históricamente el primer lugar, en cuanto a producción real se refiere, dentro del total patagónico. Pero esta posición relevante no significó un crecimiento económico del territorio por las condiciones de marginalidad socioeconómica en que se desenvolvió la actividad, y cuyas concretas posibilidades de acumulación analizaremos oportunamente.

Entre los años 1879 y 1900, las zonas noroeste y centro-oeste del territorio neuquino tuvieron posición hegemónica con relación a la ubicación específica de las poblaciones ganaderas (vacunas, ovinas y caprinas). Ello se relacionó con el lugar de asentamiento de los actores sociales involucrados en la actividad y estubo directamente vinculado con la demanda de bienes ganaderos de los centros chilenos y las modalidades de comercialización propias de toda la etapa. Para entender esta especial característica de ocupación muy localizada, es fundamental tener en cuenta una serie de condicionantes previas a la ocupación militar del espacio que ya hemos señalado. Nos referimos en especial a la existencia previa de la actividad, a su funcionamiento como parte de la región del sistema urbano chileno y a la presencia de asentamientos espontáneos de población de ese origen en el área.

$\mathrm{Al}$ respecto, es oportuno aclarar que esta última fue la corriente de población más importante que ocupó el territorio con posteridad a la campaña militar de 1879 , dedicándose a la producción de ganado menor en unidades domésticas, practicando la trashumancia y conformando 
asentamientos dispersos que poco a poco dieron la primera imagen de la organización espacial del territorio caracterizada por una marcada integración con Chile.

Además, la región noroeste poscía una infracstructura en caminos también heredada de la sociedad indígena que facilitó la perduración del modus vivendi propio de esa sociedad. Esta zona había sido antiguamente el centro de las rastrilladas indias que, cruzando el norte del territorio neuquino, se introducían en Chile. Un número importante de pasos cordilleranos permitía un rápido acceso al país trasandino facilitado por la mayor accesibilidad de la cordillera en ese sector de Neuquén, menos accidentado y carente de bosques en la zona de cruce.

Todo lo dicho sustenta la lógica ocupación primera del área centro-oeste y noroeste del Neuquén. Asimismo, permite comprender los motivos por los cuales se eligió justamente esa región para instalar la primera capital estable del territorio, Chos Malal, en un lugar geográfico privilegiado por los indígenas como nudo de circulación y tránsito. Se entiende así el criterio de seguridad y defensa militar que signó esta fundación en un momento en que se temía un enfrentamiento bélico con Chile (recuérdense las tensas relaciones argentino-chilenas hacia fines del siglo pasado).

Alrededor de principios del siglo actual se inició la ampliación de la organización social del territorio en relación a la actividad ganadera hacia la totalidad del área cordillerana y antecordillerana, definiéndose a partir de entonces la destacable especificidad de la zona sur. Ello estuvo directamente relacionado con la conformación de establecimientos ganaderos importantes con los cuales se completó la ocupación efectiva del área y con la puesta en producción capitalista de las tierras del sur del territorio (privatizadas por el estado nacional con posterioridad a las llamadas Campaña al Nahuel Huapi y a los Andes efectuadas entre 1881 y 1885). Estos establecimientos privados ocuparon las tierras de mejor calidad y aptitud ganadera del Neuquén, desalojando a los pequeños productores caprinos asentados espontáneamente en la zona. La gradual y continua puesta en producción de estas tierras - y acorde con la escala de explotación de las superficies privatizadas- provocó, consecuentemente, un incremento importante de las existencias ganaderas en el área sur del territorio, en especial vacunos y ovinos, tal y como lo demuestran los sucesivos registros censales (Ejs. Departamentos Aluminé, Huiliches, Lácar, Collón Curá y Catán Lil).

Asimismo, en una nueva concepción de la consolidación de la frontera, se dispuso, en el área, la creación de pueblos como Junín de los Andes (1883) y San Martín de los Andes (1898), localidades que se convertirían luego en centros de servicios de la población rural circundante. 
Puede sostenerse que para el año 1930 se encontraba definido, con relación a la localización de las existencias, el uso ganadero actual del suelo. Sin embargo, la crisis de la actividad habría provocado a partir de esa fecha cambios notables.

En sintesis, puede destacarse dentro de la etapa, la ocupación efectiva de tierras de propiedad particular en el sur del territorio, lo cual determinó la especificidad del área en directa relación con la importancia económica de los nuevos actores sociales vinculados a la ganadería regional. Por otra parte, se amplió, hacia el este del territorio, el área ocupada por actores sociales de menores recursos dedicados a la crianza de ganado menor, seguramente por el doble efecto del continuo incremento de la migración espontánea de población chilena y el desplazamiento de los pequeños crianceros a tierras fiscales. En este punto, cabe aclarar que, luego de la conquista militar del territorio, sólo las mejores tierras se privatizaron por sus posibilidades productivas y este proceso fue lento en lo que a su concreta ocupación se refiere. Gran parte del paisaje de la región y las especiales características del mercado demandante de la ganadería regional actuaron como limitantes para la obtención de rápidos y seguros beneficios e hicieron de Neuquén, en sus primeras épocas, una zona de escasos atractivos para el capital. Su general falta de crecimiento y riqueza, el evidente abandono del estado nacional y su débil consistencia demográfica estaban esencialmente reflejando tal realidad. En conjunto y por las razones antes mencionadas, poca tierra se privatizó en Neuquén (aún actualmente la tierra pública abarca más del $50 \%$ de la superficie provincial). Ello facilitó el mencionado asentamiento espontáneo de población de predios fiscales, generalmente chilenos y algunos descendientes directos de los antiguos dueños de la tierra, ahora despojados y considerados "intrusos" del nuevo modo de producción. Se definen así los dos actores sociales más relevantes en relación a la ganadería regional: los grandes productores propietarios de explotaciones importantes (con producción vacuna y ovina ubicada especialmente en la zona sur) y los pequeños crianceros (con producción esencialmente caprina), ocupantes de tierras fiscales dispersos por todoel interior provincial. Los medianos productores fueron, en cambio, menos representativos. Asimismo, el tener que satisfacer las necesidades básicas de la población dedicada a la actividad dominante provocó la rápida conformación de otro actor social relevante, perteneciente en este caso al sector mercantil. Se trata del "bolichero", propietario de almacén de ramos generales disperso en el área rural, cuyas primeras manifestaciones fueron los "mercachifles" ambulantes generalmente de nacionalidad sirio-libanesa. Estos comerciantes cambiaban bienes de consumo de origen chileno, mediante trueque con los pequeños y medianos 
productores, por cueros, lana y pelo que también colocaban en Chile. Sin embargo, como luego se verá en el tratamiento de los mecanismos de comercialización propios de la etapa, la posibilidad de los sectores pequenos y medianos de producción de colocar en forma directa sus mercancías en Chile les permitió cierta independencia de los grupos de intermediación comercial.

La innovación tecnológica operada en la actividad durante la etapa en estudio fue mínima, confirmando el predominio absoluto de las prácticas extensivas de la ganadería regional. Muy poco significativos fueron, por ejemplo, la utilización de alambrados y el cultivo de forrajeras. Así mismo, la perdurabilidad en el tiempo de las formas tradicionales de comercialización con Chile — prácticamente exclusivas y excluyentes hasta 1930y el destino mayoritario de tal producción (saladeros, curtiembres, graserías) no imponía demasiadas exigencias de calidad, desalentando por consiguiente el mejoramiento racial y el cercamiento de los campos. Las actividades de transformación, con sede física en Neuquén, casi no aparecen en el análisis histórico - con la sola excepción de un saladero para el consumo interno y varias queserias de fabricación familiar muy rudimentaria-. Esto implica también no olvidar la organización del espacio en función de los centros chilenos porque, indudablemente, las actividades de transformación se hacían al oeste de la cordillera en un claro ejemplo de economías complementarias entre un área de cría - Neuquén-y un área de transformación - Chile- La circulación de hombres y bienes era común en todo el espacio fronterizo, y hacia 1930 abarcaba el área cordillerana y antecordillerana en su totalidad.

Efectivamente, Neuquén cubría la insuficiencia de carne y otros derivados ganaderos como materia prima de actividades de transformación, así como lana y pelo caprino a las provincias del sur chileno - con producción en la época casi exclusivamente agrícola-; en tanto que Chile le proveía de los bienes de consumo básicos: vinos, azúcar, cerveza, licores, conservas, fideos, aguardiente, arroz, parafina, velas, jabón, maderas, artículos de mercería, tienda y papelería, té, café, harina de primera calidad, (Ministerio de relaciones exteriores, 1902). Resulta significativa la venta en Neuquén de productos de transformación de la materia prima que la misma región le proveía, tal sería el caso por ejemplo de velas y jabón. La diferencia en fletes era notable con respecto a bienes de consumo que pudiesen eventualmente llegar desde Buenos Aires, bahía Blanca o norte de Patagonia.

El comercio era exclusivamente tributario de las plazas chilenas (Valdivia, Temuco, Victoria, Los Ángeles, Chillán, Concepción, etc.) y, en razón de ello, la única moneda circulante era la del país trasandino. Esta 
situación fue común a toda la etapa, y recién alrededor de 1930 comenzó a modificarse. Ello estaría directamente vinculado a los cambios producidos en los mecanismos de comercialización a partir de esa misma fecha. Cualquier alteración en las cuestiones fronterizas tenía, por lo consiguiente, consecuencias muy serias para la región. Cuando la situación de fricción entre nuestro país y Chile se agravaba - como ocurrió hacia fines de siglo- el circulante chileno también desaparecía. En esos casos aumentaba el uso del trueque en especies o la extensión de "vales" por parte de los comerciantes en carácter de cambio a sus clientes. Lo mismo ocurría con la instalación de aduanas que, siempre coincidentemente con el recrudecimiento de los conflictos limítrofes con Chile, el estado argentino instalaba y retiraba luego, volviendo a liberalizar el comercio. En el momento en que se regulaba el control aduanero, los efectos eran inmediatos a nivel regional e involucraban a todo el espacio. Asimismo, cualquier modificación en la economía chilena se transmitía inmediatamente a la región.

En el país trasandino se colocaban animales en pie, lanas, pelo, cueros, sal, grasa, quesos y algunas plumas de avestruz en un circuito comercial que ofrecía, hasta donde hemos podido ver, las siguientes variantes: a través de agentes comerciales chilenos que periódicamente visitaban puntos estratégicos de la región y compraban in situ la producción; mediante arreos de los productores hasta los principales mercados chilenos (en especial la feria agropecuaria que anualmente se realizaba en Chillán o la Sociedad de Abasto de la ciudad de Concepción); o en acuerdos comerciales realizados en los hitos fronterizos donde los productores aprovechaban para colocar, hacia fines de la temporada estival, la hacienda engordada en las veranadas.

Si bien la mayor acumulación de excedentes parece haberse producido en Chile y no en la región, la situación de los ganaderos locales en la época, que como productores eran dependientes y su tasa de beneficio estaba regulada por los sectores comerciales de Chile, denota que esa dependencia adquiría formas distintas e intensidades diferentes fundamentadas en sus posibilidades de acumulación e inversión y en la apropiación del trabajo excedentario de los grupos sociales subordinados (indios, chilenos, mestizos, etc.). Es decir, aquellos productores con posibilidades de conducir directamente sus ganados a las ferias chilenas mediante grandes arreos que

6 Cfr. Arze Bastidas, A., Señores de la tierra, Santiago de Chile, 1953; LaFontaine, E.A., Quijote de poncho, Bs. As., Kraft, 1968; Carrasco, Gabriel, De Buenos Aires al Neuquén: reseña geográfica, industrial y administrativa, Bs. As., s/e, 1902. También avisos publicitarios sobre el funcionamiento de la Sociedad de Abasto de la ciudad de Concepción, Chile, en perí́dico Neuquén, $1^{2}$ de abril de 1894. 
implicaban necesariamente la contratación de mano de obra, estaban demostrando mejores condiciones económicas que se traducían en su mayor capacidad de negociación y, por lo consiguiente, mejores tasas de ganancia. En cambio, los pequef́os y medianos productores que vendían directamente en la veranada a los compradores chilenos y que entregaban parte de su producción en invierno (lanas, cueros) al "bolichero" a cambio de los artículos de consumo familiar, tenían menor capacidad de negociación y, consecuentemente, menores posibilidades de acumulación. Pero este último sector productivo de la ganadería neuquina tuvo en estas primeras etapas históricas una ventaja especial que radicaba en la relativa independencia que le otorgaba la posibilidad de intercambio directo con Chile, casi sin intervención alguna de los niveles intermedios de comercialización, situación que se modificaría en la etapa inmediata posterior.

En la figura 1 se ha tratado de mostrar para las primeras etapas históricas el flujo de los bienes producidos en Neuquén y colocados en Chile, según se trate de grandes productores o unidades medianas y pequeñas de producción.

La llegada del Ferrocarril Sud a la confluencia (1902) y su posterior extensión a Zapala (zona centro) en 1913, suele considerarse el primer elemento disruptor de este intercambio comercial exclusivo de toda la zona cordillerana con Chile. Sin embargo, no parece haber actuado en forma definitiva sobre el interior del territorio. El inmediato cambio de la capital al vértice este (Neuquén, 1904) hizo perder a Chos Malal su posición política, hecho que se tradujo en la disminución de su población y su transformación en un mero centro de servicios del área rural de influencia. El dinamismo que de algún modo caracterizó a la región noroeste en sus primeras etapas, en relación con su posición política, sufrió un impacto con la nueva situación coyuntural, aunque no modificó los contactos económicos con Chile y los mantuvo con pocas alteraciones hasta la década de 1930. La llegada del ferrocarril y la pérdida de posición política no significaron la inmediata vinculación del área cordillerana y antecordillerana con los mercados nacionales. Esta conservó su relación comercial con Chile, manteniéndose independiente del proceso de integración con la economía nacional —que el avance de las comunicaciones y el surgimiento de otras actividades significó para distintas áreas del territorio, en especial la zona de confluencia-.

En resumen, las características de la actividad y las modalidades de acumulación que hemos descrito determinaron un patrón de asentamientos específico para la etapa 1879-1930, con sus consecuencias socioeconómicas derivadas. La práctica absolutamente extensiva de la actividad ganadera generó una estructuración muy débil de la región y una organización 


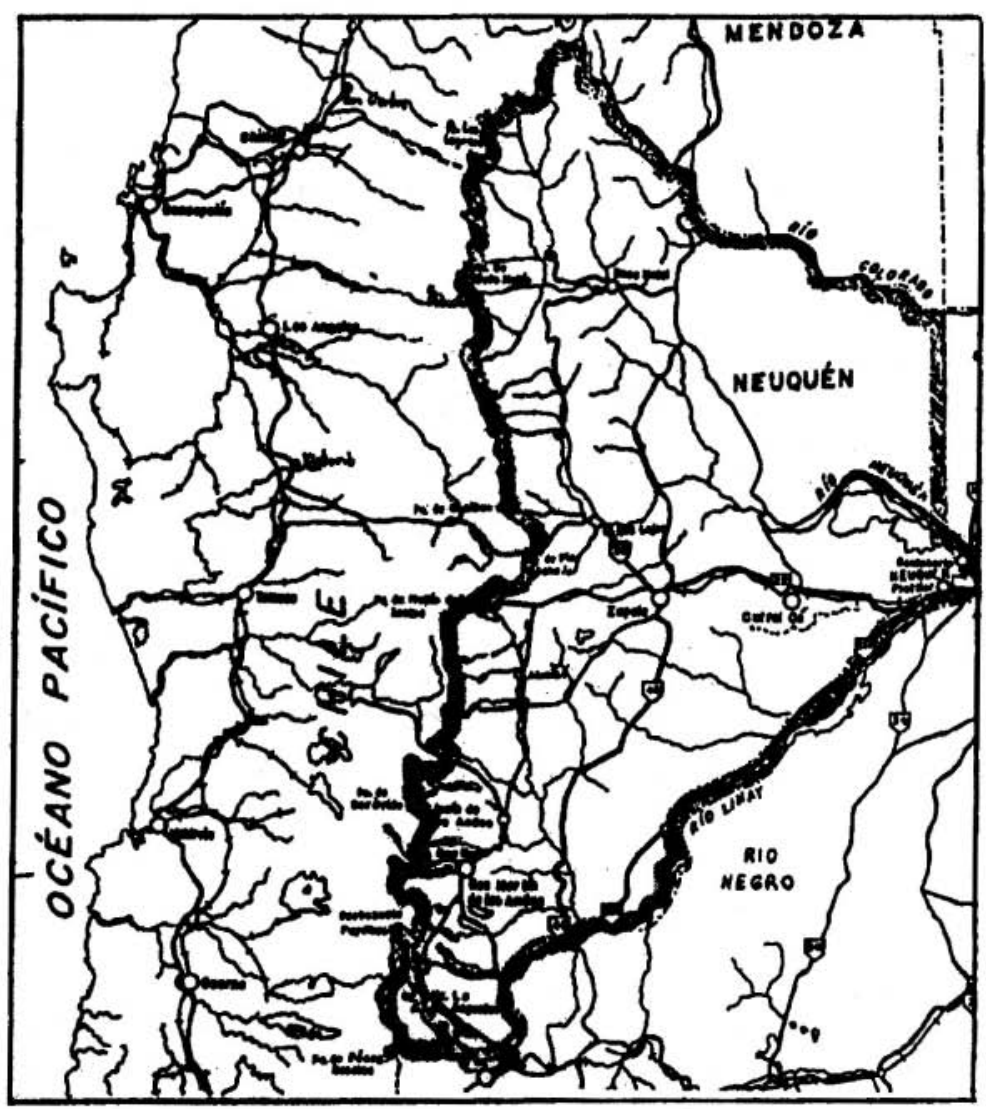

Fuente: Atlas de la provincia del Neuquén. Departamento de Geografía UNC-COPADE. p.13.

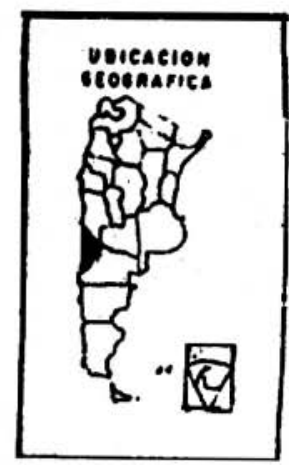

FIGURA 1. Provincia del Neuquén (Rca. Argentina). Región fronteriza argentino-chilena en el norte de la Patagonia. 
social acorde con el funcionamiento espacial de la misma. La persistencia de la vinculación con Chile, como característica heredada de la formación social indígena, determinó una mayor organización social del área oeste del territorio, que funcionó como región de centros chilenos sin alterarse con la ocupación militar del espacio ni con la imposición, por parte del estado argentino, de límites fronterizos y centros administrativos de control. Por eso, las únicas localidades que registran actos funcionales respondieron a una voluntad política de reorganizar el territorio de una forma diferente, con un carácter puramente administrativo que no cambió las relaciones sociales imperantes. Por el contrario, las características de la actividad dominante y las relaciones sociales descritas en las primeras etapas de la evolución histórica neuquina provocaron, por un lado, el surgimiento de unas pocas empresas de propietarios de grandes extensiones de tierra y, por el otro, una gran cantidad de pequeños asentamientos espontáneos en tierras fiscales - pequeñas unidades productivas-, en lugares aptos para la invernada de ganado menor. Estas últimas sufrirían, según veremos, consecuencias definitivas en su rol a partir de la crisis desencadenada por el cierre de la frontera con Chile.

\section{LA CRISIS DE LA ACTIVIDAD Y SUS CONSECUENCIAS}

Ya sobre los inicios de la década de 1930 se evidenciaban los signos de lo que las fuentes documentales llaman el "gran quebranto de la región cordillerana". La supresión de las franquicias comerciales, por aplicación de políticas estatales chilenas y argentinas, afectaron seriamente el desenvolvimiento espacial de la actividad y su funcionamiento tal cual se describiera en la etapa anterior.

Por efectos de la crisis internacional y la consecuente toma de medidas proteccionistas, a partir de 1930 se aplicaron severos controles aduaneros. A la fijación de un alto impuesto de internación al ganado trasandino, por parte del estado chileno, en 1931 se sumó uno adicional del 10\% a las mercaderías de importación (Anales de Legislación Argentina, T. 1920-1940: 253-254) dispuesto por el gobiemo argentino. La cuestión se agravó por aplicación de los acuerdos de ese mismo año sobre control de cambios, a partir de los cuales comerciantes y productores ganaderos debían necesariamente detenerse en la frontera a efectos de que se les entregase la documentación de tránsito correspondiente. Es decir, debían cumplirse los requisitos impositivos antes de realizar la operación comercial. ${ }^{7}$ Esto alteró sensiblemente el modus

7 Consultese: Archivo Histórico Provincial, Libro copiador de notas al ministerio del interior, 10/10/1932 al 9/9/1935. Nota del 11 de enero de 1933, fo. 82 . 
operandi de la región cordillerana, donde nunca las transacciones de este tipo se hacían en forma anticipada ni definitiva hasta tanto no se produjese el encuentro físico de compradores y vendedores chilenos o argentinos.

Estas decisiones políticas estatales provocaron una verdadera paralización de las transacciones comerciales, lo cual claramente afectó por igual a toda la zona cordillerana y antecordillerana del Neuquén, que había funcionado tradicionalmente como región que respondía a la demanda de centros y puertos chilenos. Años más tarde, en la década de los cuarenta, la situación tuvo un corte aún más definitivo, cuando la fase de industrialización de la economía nacional argentina estableció mayores barreras aduaneras en el área, con lo cual se terminó de descomponer el mercado específico de una importante área del interior neuquino.

Ambos estados, en diferentes etapas y por distintas razones inherentes a sus propias circunstancias históricas y derivadas de la coyuntura internacional, consolidaron sus situaciones territoriales a través de la fijación de una frontera comercial. Según veremos, este factor condicionante provocó disímiles consecuencias en los distintos actores sociales. Las posibilidades de modificar comportamientos y acceder a diferentes alternativas económicas por parte de las empresas productivas, ya sea que se trate de grandes productores o unidades pequeñas y medianas de producción, dependerá de su mayor o menor posición de poder dentro de las relaciones directas de acumulación vigentes en la actividad. Así fue como las posibilidades de acumulación de los pequeños y medianos productores disminuyeron progresivamente a medida que el intercambio que efectuaban de manera directa hasta 1930 con Chile se interrumpía.

La crisis provocada por la descomposición de las modalidades de comercialización se evidencia en las existencias totales de ganado, que sólo en algunos casos (bovinos) aparecen recuperándose en etapas muy actuales, posiblemente por la incidencia de una serie de factores que habrían provocado signos de recuperación de la ganadería vacuna regional hacia mediados de la década de $1970 .^{9}$

8 A partir de 1945, el gobiemo argentino dispuso una severa fiscalización al tráfico internacional con Chile. Normas rígidas del Banco Central reglamentaron la importación y exportación, exigiendo un depósito previo en divisas en relación al valor de los productos a exportar. Los efectos de estas medidas sobre la descomposición del mercado tradicional de la ganadería neuquina pueden verse, entre otros, en el Libro histórico No.1 de la Escuela Nacional $N^{2} 15$ de Chos Malal, Neuquén, fundada en 1887, actual Escuela de Frontera $N^{2} 3$, manuscrito, 1946, fo. 32 .

9 Dichos signos de recuperación podrían atribuirse, entre otros, a la puesta en marcha del "Programa de esquila y comercialización lanera de la provincia del Neuquén" (1975); a la instalación de la barrera sanitaria para preservar libre de aftosa a la región al sur del río Colorado (1976) y a diversos intentos cooperativos de comercialización por parte de pequeños y medianos productores ganaderos del interior provincial. (veáse Bandieri, 1988: 226-230). 
El censo ganadero de 1930 registró, luego de una etapa de crecimiento sostenido, un total de 156,591 cabezas de ganado bovino para el territorio del Neuquén. Esta cifra disminuyó en forma apenas significativa hacia 1937 y en cantidad mucho más notable en el año 1947, manteniendo una fuerte tendencia a la baja hasta el censo ganadero de $1970(123,831$ cabezas). Sólo en el último registro censal del año 1978 las existencias totales de ganado bovino en Neuquén $(186,907)$ superaron la cifra de 1930 oportunamente consignada.

Con respecto al ovino, hacia 1930-1937 se registraron las cantidades más altas de existencias totales en el territorio, también fue evidente el deterioro creciente de la actividad en los años posteriores, ya que hasta la fecha, nunca se han vuelto a alcanzar los niveles totales mencionados. En un análisis comparado de las existencias ovinas por departamentos se evidencian, en la etapa posterior a 1930, importantes cambios en la localización de la actividad. En especial, cabe seffalar el caso de la zona sudoeste, que en la etapa anterior ubicáramos como la de mayor producción vacuna-ovina y que a partir de 1930 conservó una primera posición en vacunos pero perdió gradual y sostenidamente sus existencias ovinas, proceso muy evidente ya hacia mediados de la década de 1930. Se sostiene, en este caso, que la mayor posibilidad de acumulación permitió a las grandes unidades ganaderas del área modificar sus opciones productivas en una coyuntura histórica especialmente desfavorable para la ganadería en general y para el ovino en particular. Situación similar reflejaría parte del área sudeste - predominantemente ovina hasta 1930 - donde departamentos como Collón Curá muestran a partir de esa fecha un claro incremento de sus existencias vacunas.

$\mathrm{Al}$ respecto, recuérdese que a la crisis general de la actividad ganadera regional, por la supresión de las franquicias comerciales con Chile, se le unió, hacia la misma época (1937), el deterioro del precio internacional de la lana; situación que se agravaría aún más al finalizar la segunda guerra mundial con signos evidentes de estancamiento hasta la actualidad. Asimismo, téngase presente, en relación con lo anterior, el continuo retroceso de la producción lanera argentina cuyas variaciones más importantes respecto al volumen físico se produjeron a fines de la década de 1960 y se acentuaron en la siguiente. Ello concuerda con el deterioro de los precios internacionales y las políticas cambiarias desfavorables. Según trabajos puntuales referidos a la actividad, las causas principales de tal deterioro serían el proceso de depresión de los mercados laneros por la utilización de fibras sintéticas y la incapacidad de Argentina para defender mercados tradicionales y conquistar nuevos.

Con respecto al caprino, es evidente el gran aumento reflejado en la zona noroeste. El departamento Minas es un claro ejemplo, a través de la 
disminución de sus existencias vacunas se da un leve incremento ovino y una marcada tendencia a la caprinización, que alcanza el $11.5 \%$ de las existencias totales de la provincia según el último registro censal de 1978; esto como consecuencia de un incremento sostenido a partir de la década de los cuarenta. En este caso, el cierre definitivo de la frontera en esos años habría provocado consecuencias socioeconómicas más serias, acordes con el predominio de actores sociales de menor capacidad de acumulación. Los departamentos cordilleranos desde Aluminé, al sur, han decrecido en forma gradual hasta alcanzar porcentajes escasamente representativos en el censo de 1978, superando pocas veces el $1 \%$ de las existencias totales del territorio. La participación de la zona sur, a nivel producción general caprina, es muy inferior ya desde la década de 1930 según se desprende de las cifras censales y continúa hasta la actualidad (Ejs. Lácar $0.2 \%$, Los Lagos $0.1 \%$, según censo 1978). También este proceso estaría directamente vinculado a las posibilidades de acumulación de las empresas ganaderas del área, favorecida por la creación de parques nacionales en la década de 1930 que prácticamente erradicó en forma total a los pequeños crianceros, con la sola excepción de algunas pocas reservas indígenas legalmente reconocidas que sobreviven en graves condiciones de marginalidad socioeconómica.

En resumen, pueden señalarse una serie de cambios operados en la localización de las poblaciones ganaderas, que en principio coinciden con la crisis operada en las modalidades de comercialización luego de 1930 y cuyos efectos más importantes se evidencian alrededor del año 1947. Del análisis anterior se desprende una clara tendencia a la caprinización del área noroeste zona que, sin embargo, presenta aptitudes naturales para vacunos y ovinos. Asimismo, es clara la predominancia vacuna en el sudoeste donde todas las unidades censales (departamentos), antes de 1930, aparecen erradicando al caprino y después de esa fecha, en un proceso que se acentúa hacia fines de la década de 1940, también al ovino. Esto último en directa relación con la pérdida del precio internacional de la lana. Un proceso similar parece sufrir la zona del centro-oeste, aunque restringido sólo a algunos departamentos, justamente aquéllos que registran explotaciones de mayor significatividad económica (Ej. Loncopué). La zona sudeste, que en la etapa anterior se había manifestado con clara predominancia ovina, en los últimos años, a partir de la década de los setenta, ha ido entrando gradualmente en un proceso de cambio de sus producciones ganaderas. Es así como en Catán Lil se nota una marcada tendencia hacia la caprinización y en Collón Curá una importante orientación al vacuno. Ello implicó, a corto plazo, la redefinición en cuanto al uso ganadero de un área considerada actualmente como predominantemente ovina. 
Con respecto a los cambios mencionados, sostenemos que la reorientación de los flujos comerciales hacia las décadas de 1930-1940 y la degradación de suelo y vegetación, como consecuencia del sobrepoblamiento, serían las causas directas de los cambios productivos señalados para la zona noroeste; en tanto que en el sudoeste y sudeste, la pérdida de rentabilidad del lanar sería el factor determinante del cambio de actividad. Asimismo, que el aumento de la caprinización, o la situación inversa de reemplazo del lanar por el vacuno, estaría directamente vinculada a la alternativa de cambio que el poder de acumulación permitió frente a la crisis de las distintas unidades ganaderas. Ello determinó la diferencia entre la zona sur y su especialización vacuna y la zona norte y su gradual caprinización, así como sus efectos a nivel de modalidades de asentamiento y despoblamiento de algunas áreas rurales de la provincia.

En tanto el fuerte de la actividad en la región es la etapa de cría, la ganadería conservó las características de producción extensiva sin modificar sustancialmente las formas tecnológicas del manejo ganadero señaladas en la etapa anterior. Sin embargo, a partir de la década de 1930, puede evidenciarse una mayor tendencia a la mestización y mejoramiento racial de vacunos y ovinos en las grandes empresas productoras como forma de asegurar las posibilidades de colocación en el mercado nacional, una vez interrumpida la conexión comercial con Chile.

Es necesario remarcar que, a partir de la modificación del sistema de comercialización por decisiones de política estatal producido durante las décadas de 1930-1940, surgen cambios en la posición de los actores sociales vinculados a la ganadería regional y su rol en el proceso productivo, así como nuevos actores sociales vinculados a la reestructuración de las relaciones comerciales.

La situación de paralización del comercio con Chile afectó por igual a todos los estratos productivos pero, obviamente, produjo consecuencias socioeconómicas más graves en el pequeño productor, actor social más relevante en las zonas noroeste, centro y este del territorio. Aunque menos gravemente, dada la escala de producción de las empresas más representativas del área, los perjuicios ocasionados por la crisis afectaron también a los grandes productorés característicos de la zona sur. Estos establecimientos, generalmente sociedades anónimas, dedicadas fundamentalmente al vacuno, también se vieron seriamente perjudicados por los impuestos que gravaban la importación en las aduanas chilenas y el bajo precio de las haciendas en los mercados nacionales.

Ante la crítica situación descrita, la única alternativa posible para los productores locales parece haber sido su inserción en el mercado nacional, tema por demás complicado si se tiene en cuenta, por un lado, la desvalo- 
rización de precios de las haciendas como consecuencia de la crisis internacional y, por el otro, la inexistencia de un sistema integrado de comunicaciones con el área del Atlántico (veáse Banieri y Bonnahom, 1983). Esto último motivado, según puede deducirse, por la perduración hasta 1930 del tradicional funcionamiento de la región en atención a la demanda del área del Pacifico. De tal manera, la única forma viable de canalizar el ganado del interior neuquino hacia los mercados del Atlántico era embarcando las haciendas por ferrocarril, en especial en la estación Zapala (punta de rieles ubicada en el centro del territorio). Pero tal operación insumía, según mencionan los documentos consultados, altísimos fletes que disminuían notablemente los beneficios del productor. ${ }^{10}$ Dichas fuentes seffalan, a partir de 1930 , un aumento importante de la salida de hacienda y frutos del país hacia los mercados de Bahía Blanca y Buenos Aires. Esto corrobora nuestra hipotesis de que a partir de los controles aduaneros impuestos se visualiza la canalización de gran parte del flujo comercial del interior del territorio hacia centros del mercado nacional, trastocándose el tradicional funcionamiento del espacio.

Ambas situaciones, la interrupción del comercio con Chile y el alto precio de los fletes ferroviarios, afectaron por igual a todos los productores ganaderos. No obstante, los grandes productores pudieron acceder rápidamente a mecanismos de solución que el mismo sistema les aseguraba. En el año 1933, ante reiteradas solicitudes, el Banco Nación accedió a suspender por un año los compromisos de pago, abonando los intereses corrientes “...por el quebranto económico que sufre la precordillera por la paralización del comercio con Chile y la depreciación del ganado y frutos del país" (Archivo Histórico Pcial., Libro copiador varios, 4/3/1933 al $1 \% / 10 / 1933$, nota del 10 de julio de 1933). También se hicieron gestiones oficiales ante la administración del Ferrocarril Sud para la obtención de rebajas de fletes para el transporte de haciendas desde Zapala con destino a invernada en Buenos Aires a lo cual la empresa accedió fijando tarifas especiales. Resulta evidente que estas medidas favorecieron únicamente a los grandes productores con acceso al sistema de créditos y a aquéllos que vendían ganado vacuno para invernar en Buenos Aires, o bien, como empezaba a ser común entre los productores vacunos de la zona sur, a aquéllos que eran propietarios simultáneamente de campos en la provincia de Buenos Aires donde completaban la etapa de engorde.

10 Archivo Histórico Provincial, Libro copiador de notas al M.I., informe fechado en febrero de 1933, fo. 175. Iguales conceptos se repiten en la memoria presentada al Superior Gobiemo de la Nación por el gobernador E. Pilotto, año 1934, fo. 105. 
Hacia 1940 muy poca hacienda salía para Chile, y pocos af́os más tarde no había más exportación. Efectivamente, a partir de 1945, el gobierno argentino dispuso una severa fiscalización para el tráfico internacional con Chile. Normas rígidas del Banco Central reglamentaron la exportación e importación, exigiendo un depósito previo en divisas en relación al valor de los productos a exportar, con lo cual se terminó de descomponer el mercado tradicional de la ganadería neuquina. Igualmente se amplió la dependencia del abastecimiento nacional que para fines de la década de 1940 era total en bienes de consumo y capital, pero con un notable encarecimiento al provenir de Buenos Aires o bahía Blanca.

La severa fiscalización del tradicional tráfico comercial con Chile impuso condiciones imposibles de cumplir para medianos y pequeños productores. Resulta claro entonces que sólo a partir de las décadas de 1930 y, fundamentalmente, de 1940, se concretó la total integración de la producción ganadera regional con el mercado nacional luego de una supervivencia de siglos - si se abarca la etapa indígena - de intercambio prácticamente exclusivo con Chile, que se mantuvo en tanto existió la posibilidad concreta de colocar la producción en el país trasandino. Si bien, el contrabando siguió apareciendo como alternativa posible aunque riesgosa, dada la presencia de mayores elementos de control fronterizo, obviamente su práctica no supuso una solución para el problema, sino más bien una salida coyuntural en la medida que permitió la comercialización ilegal de cierta cantidad de ganado en Chile, de una magnitud muchísimo menor que la que había sido antes el sostén de la actividad. Los controles policiales y aduaneros impidieron definitivamente la colocación regular de grandes tropas de ganado.

Cortadas las formas tradicionales de los mercados - factor condicionante en lo que hace a la distribución y apropiación de excedentes porque modifica la capacidad de acumulación de los actores sociales-, la estrategia de reacomodamiento de las distintas empresas productoras dependió directamente de las alternativas que les ofreció su grado de poder dentro de las relaciones directas de acumulación de la actividad a partir del cambio aludido. Es decir, las grandes empresas - predominantemente vacunas y en menor medida ovinas por el abandono gradual de la actividad- que pudieron prescindir de la intermediación comercial, ubicadas sobre todo en el área cordillerana centro y sur, tuvieron alternativas válidas para obtener al menos una tasa de beneficios que les permitió mantenerse en la actividad, a pesar de la crisis del sistema tradicional de comercialización (ej. reemplazo de ovino por vacuno, complementación con engorde en la provincia de Buenos Aires, etc.). En cambio las pequeñas unidades productivas dependieron cada vez más de una serie de agentes intermediarios 
en el proceso de comercialización, que son los que en definitiva generaron los primeros agregados económicos de la actividad con relación, particularmente, a los pequeños productores.

En todo este proceso, la zona noroeste fue sin duda la más perjudicada. Como es lógico, a partir de 1930 cesó la circulación de moneda chilena. Los sectores mercantiles buscaron su reacomodo en vías alternativas de circulación (Mendoza, Zapala, General Roca). Los sectores productivos del área - mayoritariamente pequeños-, al no tener posibilidades de desplazamiento productivo, incrementaron su marginalidad y perdieron las formas independientes de comercialización ya descritas. Es decir, la desvalorización de las haciendas y sus subproductos (lanas, cueros, pelo, etc.) y la paralización del comercio con Chile obligó a los pequeños productores a entregar sus productos ya desvalorizados en trueque al comercio local a cambio de artículos de consumo argentinos notablemente encarecidos. Se intensificaron así relaciones sociales precapitalistas de producción que persisten hasta la actualidad, lo cual se explica por la lógica interna del sistema en tanto los comerciantes, al entrar en un circuito más amplio donde la cadena de intermediación se amplía, necesitan la oferta de productores con restringido poder de negociación que les permita mantener un margen de beneficios. Estos sectores mercantiles se transformaron, a partir de las décadas de 1930-1940 en la única vía posible de acceso al mercado nacional de los pequeños productores. De esta manera, ampliaron su base de operaciones en la búsqueda de mayores beneficios y junto con los grandes empresarios ganaderos, conformaron las estructuras locales de poder. Además —en tanto la proporción mayor de excedentes beneficia a otros agentes ubicados fuera del ámbito regional- favorecicron la persistencia de la forma social de producción y, en su carácter de burguesía local, incrementaron su poder político a partir de la provincialización del territorio sobre mediados de la década de 1950.

La fucrte presencia de la intermediación puede visualizarse claramente en las modalidades actuales de comercialización de la actividad ganadera regional, en especial aquéllas relacionadas con las empresas productoras medianas y pequefas. Estas últimas, por su parte, han visto en los últimos años consolidarse sus características de absoluta subsistencia ante la imposibilidad social de generar excedentes (veáse: Bandieri, 1988).

\section{CONCLUSIONES}

La interrupción definitiva del comercio libre con Chile, por las medidas aduaneras que ambos países tomaron durante las décadas de 1930 y 1940 , provocó la destrucción de las principales relaciones comerciales que 
definían la organización social y su expresión espacial y que el determinante estructural de la crisis de la actividad ganadera regional profundizo en años posteriores.

Frente a la crisis, los actores sociales relacionados con la actividad ganadera tuvieron distintas alternativas directamente relacionadas con sus posibilidades de acumulación y consecuente peso en las relaciones de poder a nivel regional.

Las pequeñas unidades productivas, surgidas de la ocupación espontánea de tierras fiscales y mayoritarias en las zonas del centro y noroeste neuquino, a través de la comercialización directa con Chile y mientras ésta se mantuvo, tuvieron cierta independencia relativa en las relaciones de acumulación y vieron seriamente afectadas sus modalidades de comercialización.

Así, la posibilidad de colocar la producción ganadera en otros centros dependió de la presencia de sucesivos intermediarios en la etapa de comercialización, quienes se convirtieron en el eslabón imprescindible de acceso al mercado de estas unidades productoras que consolidaron sus características de absoluta subsistencia.

Consecuentemente, esos acopiadores de la producción primaria de gran parte del área rural neuquina vieron incrementadas sus posibilidades de acumulación, pasando a ocupar un importante lugar en las estructuras de poder a nivel regional y constituyéndose en uno de los componentes más destacados de la burguesía local.

Las mismas formas de producción imperantes provocaron la supervivencia de las economías de subsistencia con formas relictuales de organización precapitalista, lo cual está directamente ligado a su imposibilidad de generar excedentes y deviene en la falta de innovación tecnológica provocando, consecuentemente, el incremento del grado de marginalidad e impidiendo el cambio de actividad. En otras palabras, la imposibilidad de generar de unos es la condición de generar de otros.

Por consiguiente, a estos pequeños productores sólo les quedan dos alternativas: mantenerse en el predio para asegurar la subsistencia o migrar a los centros urbanos para integrarse a la oferta de mano de obra en otro tipo de actividad. Ello explicaría el despoblamiento rural neuquino iniciado hacia la década de 1940. 


\section{BIBLIOGRAFÍA}

ASSADOURIAN, Carlos S. 1982. El sistema de la economía regional. Mercado interno, regiones y espacio económico. Lima, IEP.

BANDIERI, Susana, 1983. "Evolución histórica de la ganadería y su distribución por zona", en: Neuquén, un siglo de historia. Neuquén, CALF-Gráfica Modelo.

BANDIERI, Susana, 1988. "Condicionantes históricos del asentamiento humano en Neuquén: consecuencias socioeconómicas". Informe final beca de perfeccionamiento presentado al CONICET en abril 1988 (inédito).

BANDIERI, S. y M.C. Angelini. 1982. Evolución de las existencias ganaderas neuquinas entre 1895 y 1937. Publicación de las IV jornadas de historia económica argentina. Río Cuarto, Córdoba.

BANDIERI, S. y Emma Bonnahom. 1983. "Neuquén, un territorio incomunicado". en: Neuquén, un siglo de historia. Neuquén, CALF-Gráfica Modelo.

DESTEFANO DE MONSALVO, Beatriz. 1980. Actividad caprina en el norte neuquino. Tesis de licenciatura, Dpto. de Geografía, Facultad de Humanidades, UNC, (inédito).

GIUSTI, V. 1984. Sistema de comercialización de ganado en pie en la provincia del Neuquén, OEA, Proyecto de cooperación técnica para el desarrollo de la región sur, Neuquén, (mimeo).

GUÍA COMERCIAL EDEIMAN, 1924-1925. Informe sobre ganaderia, agricultura, comercio, industria, etc., territorio del Neuquén y parte de río Negro. Buenos Aires, Taller gráfico Neumann y Cia.

MINISTERIO DE RELACIONES EXTERIORES. 1902. "Informe del cónsul general de Chile en la República Argentina", en: Boletín del Ministerio de Relaciones Exteriores. Santiago de Chile, 1er. semestre.

OLASCOAGA, Manuel J. 1974. Estudio topográfico de la Pampa y río Negro. Buenos Aires, Eudeba.

SIRI, Antonio F. 1983. Sistema provincial de comercializacion de productos ganaderos. Informe técnico, OEA. Neuquén, noviembre (mimeo).

UTZ-BAHN (consultores OEA). 1983. Desarrollo predial de la producción ganadera en el área norte-provincia del Neuquén. Neuquén, febrero (mimeo).

YAZMAN, James A. (consultor OEA). 1983. Perfil de un plan de mejoramiento de la producción caprina en la zona norte de la provincia del Neuquén, Neuquén, marzo (mimeo). 